To the Editors:

\title{
Practice of self-medication with antibiotics in the Colombo district, Sri Lanka
}

\author{
G P S G Senadheera' ${ }^{1,3}$, S Sri Ranganathan ${ }^{3}$, N S Gunawardane ${ }^{4}$, G H Fernando 2 , B M R Fernandopulle ${ }^{5}$
}

Ceylon Medical Journal 2017; 62: 70-72

DOI: http://doi.org/10.4038/cmj.v62i1.8439

Self-medication is defined as "the use of drugs to treat self-diagnosed disorders or symptoms or the intermittent or continued use of a prescribed drug for chronic or recurrent disease or symptoms" [1]. Selfmedication with antibiotics (SMA) may lead to antibiotic resistance as the consumed antibiotic could be incorrect, inappropriate, excessive, unnecessary or inadequate. This study aims to determine the period prevalence of SMA in the Colombo District and to describe the reasons for SMA, its utilization pattern and socio-economical determinants.

A cross-sectional descriptive community survey was conducted in the Colombo District. The study population comprised of adults over 18 years who have been residing in the Colombo district for at least a month before data collection and judged to be competent to respond to the questionnaire.

Sample size was determined by the formula to estimate a population proportion [2]. Prevalence of SMA in Colombo was assumed to be $50 \%$. A design effect of 1.5 was incorported to account for the cluster sampling technique and a further $5 \%$ was added for non-responders. The estimated sample size of 605 was adequate to estimate the prevalence to within 5\% with 95\% confidence.

Colombo District is divided into 13 Divisional Secretariats (DS) and 557 Gramaniladari divisions (GNDs). Twenty four GNDs were included using probability proportional to size sampling technique from six randomly selected DS divisions. From each GND, 25 households were selected. The index household was randomly selected using the voters' list. Houses located on the same side of the road were included till 25 were recruited and one eligible adult was randomly selected from each of the 25 households using a systematic grid. Data were collected using an interviewer administered questionnaire after getting informed written consent. The study was conducted over a two month period in early 2015.

The questionnaire was developed by analysing previous studies and by consulting experts. It included both open and close ended questions on demographic data, practice of SMA and its co-variants. Face and content validity of the questionnaire was established. Questionnaire was pre-tested and data collection process was piloted.

Data were analysed using Statistical Package for the Social Sciences (SPSS) version 17. Both descriptive and inferential statistics were employed. Prevalence of SMA was calculated by dividing the number who used an antibiotic without a valid prescription (SMA) in the last 3 months by the total respondent. Valid prescription was defined as that issued by a medical practitioner or dentist registered under the medical ordinance. Antibiotic use was meticulously verified by many ways; asking to name the antibiotic, posing indirect questions, checking the left over medicines, by inspecting empty bottles, envelopes, or old prescriptions. Ethical approval was obtained from the Ethics Review Committee of Faculty of Medicine, University of Colombo (EC-14-035).

Of the 607 respondents, 158 (26\%) had used an antibiotic during last 3 months, of them 118 had a valid prescription and 41 had self-medicated. The period prevalence of SMA was 6.8\% (95\% CI=4.89-9.05); 6\% in women and $8.4 \%$ in men. In men, prevalence of SMA was relatively higher in employed individuals (10.6\%) than in students $(7.7 \%)$, but it was the opposite in women $(8.7 \%$ vs. 14.3\%). A systematic review from 19 developing countries over a period of 10 years (2002-2012) reported a prevalence of SMA of $38.8 \%$ [4]. Compared to which

Departments of ${ }^{1}$ Allied Health Sciences and ${ }^{2}$ Pharmacology, Faculty of Medical Sciences, University of Sri Jayewardenepura, Departments of ${ }^{3}$ Pharmacology and ${ }^{4}$ Community Medicine, Faculty of Medicine, University of Colombo, ${ }^{5}$ Department of Para clinical, General Sir John Kotelawala Defence University, Ratmalana, Sri Lanka.

Correspondence:GPSGS, e-mail: <savini@sjp.ac.Ik>. Received 29 September 2016 and revised version accepted 23 January 2017.

This is an open-access article distributed under the terms of the Creative Commons Attribution License, which permits unrestricted use, distribution, and reproduction in any medium, provided the original author and source are credited. 
SMA in our study population appears to be low even after leaving allowances for methodological differences. This low prevalence of SMA in the Colombo District may have been due to easy accessibility to state or private hospitals and clinics.

A relatively large number $(\mathrm{N}=371,61 \%)$ claimed they knew the term antibiotic, however only 149 (24.5\%) managed to name an antibiotic correctly. Ten percent named brand names of paracetamol and chlorpheniramine as antibiotics. Amoxicillin was the most commonly known antibiotic (92\%).

Table 1 shows SMA in different demographic and socioeconomic groups. Prevalence of SMA was significantly related to younger age of 18 -34 years $\left(\chi^{2}=8.680\right.$, $\mathrm{df}=1, p=0.003)$, being employed $\left(\chi^{2}=4.581, \mathrm{df}=1\right.$, $p=0.032)$, an education level above G.C.E. A/L $\left(\chi^{2}=11.870, \mathrm{df}=1, p=0.001\right)$ and being able to name an antibiotic correctly $\left(\chi^{2}=16.889, \mathrm{df}=1, p<0.001\right)$.
However when binary logistic regression analysis was done to control confounding effects, only age between 18-34 years (OR 2.68, $p=0.013$ ) and being able to name an antibiotic correctly (OR 2.96, $p=0.002$ ) were associated with SMA.

The 41 respondents who self-medicated used a range of different antibiotics with some taking more than one antibiotic. Majority had taken amoxicillin ( $\mathrm{N}=34$, 82.9\%), few had taken cephalexin, phenoxymethylpenicillin, azithromycin, nitrofurantoin, cloxacillin, coamoxiclav, clarithromycin or erythromycin. Median duration of SMA was 3 days (1-7 days). Only 25\% of those self-medicating with amoxicillin had taken it inappropriately. The majority claimed that they SMA for upper respiratory symptoms (68\%), fever (19.5\%), wounds $(9.8 \%)$ or urinary symptoms (2\%). Table 2 describes reasons for SMA, source of antibiotic, guidance for SMA, factors considered in selecting an antibiotic, source of instructions and decision to stop the antibiotic.

Table 1. Distribution of self-medication with antibiotics by different demographic and socioeconomic characteristics

\begin{tabular}{|c|c|c|c|c|c|c|}
\hline \multirow[t]{2}{*}{ Characteristic } & \multicolumn{2}{|c|}{$\begin{array}{l}\text { Self-medicated } \\
\qquad(N=41)\end{array}$} & \multicolumn{2}{|c|}{$\begin{array}{l}\text { Non self-medicated } \\
\quad(N=566)\end{array}$} & \multirow[t]{2}{*}{$\begin{array}{l}\text { Total } \\
(N=607)\end{array}$} & OR(95\% CI) \\
\hline & & & & & & \\
\hline Female* & 25 & (6) & 392 & $(94.0)$ & 417 & $(0.75-2.77)$ \\
\hline Male & 16 & (8.4) & 174 & $(91.6)$ & 190 & \\
\hline \multicolumn{7}{|l|}{ Age group in years } \\
\hline $18-34$ & 19 & $(11.7)$ & 143 & (88.3) & 162 & $2.56(1.346-4.86)$ \\
\hline 35 and above * & 22 & $(4.9)$ & 423 & (95.1) & 445 & \\
\hline \multicolumn{7}{|l|}{ Education level } \\
\hline Up to GCE O/L* & 14 & (3.9) & 348 & (96.8) & 362 & $3.08(1.58-6.00)$ \\
\hline $\mathrm{A} / \mathrm{L}$ above & 37 & $(11.0)$ & 218 & (89.7) & 245 & \\
\hline \multicolumn{7}{|l|}{ Employment status } \\
\hline Employed & 21 & (9.7) & 196 & (90.3) & 217 & $1.98(1.05-3.75)$ \\
\hline Unemployed * & 13 & (4.9) & 252 & (95.1) & 265 & \\
\hline \multicolumn{7}{|c|}{$\begin{array}{l}\text { Having medical insurance or } \\
\text { reimbursement for medical claim }\end{array}$} \\
\hline Yes & 14 & $(10.2)$ & 123 & (89.8) & 137 & $1.87(0.95-3.67)$ \\
\hline No* & 27 & (5.7) & 443 & (94.3) & 470 & \\
\hline \multicolumn{7}{|c|}{$\begin{array}{l}\text { Received medical treatment in the } \\
\text { last three months }\end{array}$} \\
\hline Yes* & 12 & (5.5) & 207 & $(94.5)$ & 219 & $1.39(0.67-2.79)$ \\
\hline No & 29 & (7.5) & 359 & $(92.5)$ & 388 & \\
\hline \multicolumn{7}{|c|}{ Able to name an antibiotic } \\
\hline Yes* & 21 & $(14.1)$ & 128 & $(85.9)$ & 149 & $0.28(0.15-0.53)$ \\
\hline No & 20 & $(4.4)$ & 438 & $(95.6)$ & 458 & \\
\hline \multicolumn{7}{|c|}{ Monthly average income of the family in LKRs } \\
\hline 25000 and less & 15 & (5.1) & 277 & $(94.9)$ & 292 & $0.55(0.28-1.05)$ \\
\hline 25001 and above * & 26 & $(9.0)$ & 262 & (91) & 288 & \\
\hline \multicolumn{7}{|l|}{ Household Size } \\
\hline $1-4$ & 19 & $(5.8)$ & 306 & $(94.2)$ & 325 & $0.73(0.39-1.39)$ \\
\hline $5-12 *$ & 22 & (7.8) & 260 & (92.2) & 282 & \\
\hline
\end{tabular}


Table 2. Pattern of ABA self-medication during last three months of the respondents of Colombo district $(\mathrm{N}=41)^{*}$

Variable
Reason for self - medication

Frequency

Reason for self - medication

Convenience

Past experience

Illness is mild

Easy to buy from pharmacy

My own knowledge

Cost saving

Drugs available in home

Doctor is far away

Source of obtaining antibiotics

Pharmacy

Left over from previous prescription

given to another person

Left over from previous prescription

Contact in hospital

From friend

The guidance for self-medication

Own experience

Previous prescription given to me

Pharmacist

Previous prescription given to family member

Opinion by friend/neighbour

Internet/drug information

Selection of particular ABM

From past experience

Illness

Type of antibiotic

Brand of antibiotic

Price of antibiotics

Instructions of the pharmacist

Adverse reaction safety

Side effects

From TV program/etc

Dosing instructions obtained from

From pharmacist

Previous experience

Product information leaflet

From doctor

From internet

My own knowledge

From a friend

Decision to stop ABM

Symptoms disappear

After Antibiotics ran out

Few days after recovery

Consulting the pharmacist /doctor

Completion of the course
Antibiotics cannot be dispensed without a valid prescription in Sri Lanka as they are categorised as prescription only medicine. As shown in table 2 pharmacists have contributed to this irrational practice of SMA in majority of instances (90\%). Community pharmacist have guided the public in SMA and provided information about selecting a particular antibiotic and dosing instructions. Despite the "pharmacists" providing dosing instructions, about $85 \%$ have stopped the antibiotic when the symptoms disappeared. Previous studies have also identified community pharmacists as the leading source for SMA [3,4].

The leading symptoms which led to SMA were respiratory symptoms, fever, wounds and urinary symptoms: This observation is similar to reports from other studies [3,4].

Almost one third had used previous prescriptions to buy antibiotics. Antibiotic prescriptions prescribed previously for mild self-limiting diseases have also been identified as one of the risk factor for subsequent SMA.

Our study has provided data about the practice of SMA in Colombo district and identified an important area to be addressed in antibiotic stewardship programmes.

\section{Conflicts of interest}

There are no conflicts of interest.

\section{Funding}

Higher Education for twentieth century (HETC)/ HRD grant - Ministry of Higher Education, Sri Lanka.

\section{References}

1. WHO. Guidelines of the regulatory assessment of medical products for use in self medication. Genewa: WHO, 2000.

2. Lwanga SK. Lemeshow S. Sample size determination in health studies: a practical manual. Geneva: World Health Organization; 1991.

3. Widayati A, Suryawati S, de Crespigny C, Hiller JE. Self medication with antibiotics in Yogyakarta City Indonesia: a cross sectional population-based survey. BMC res notes 2011; 4: 1 .

4. Ocan M, Obuku EA, Bwanga F, Akena D, Richard S, et al. Household antimicrobial self-medication: a systematic review and meta-analysis of the burden, risk factors and outcomes in developing countries. BMC public health 2015; 15: 1. 